\title{
Association between patients' beliefs and oral antidiabetic medication adherence in a Chinese type 2 diabetic population
}

This article was published in the following Dove Press journal:

Patient Preference and Adherence

27 June 2016

Number of times this article has been viewed

\author{
Ping $\mathrm{Wu}^{\prime}$ \\ Naifeng Liu \\ 'Department of Clinical Pharmacy, \\ School of Basic Medical Sciences \\ and Clinical Pharmacy, China \\ Pharmaceutical University, ${ }^{2}$ Institute \\ of Cardiovascular Disease, Southeast \\ University Medical School, Nanjing, \\ People's Republic of China
}

Purpose: The objective of this study was to identify, using the theory of planned behavior (TPB), patients' beliefs about taking oral antidiabetic drugs (OADs) as prescribed, and to measure the correlations between beliefs and medication adherence.

Patients and methods: We performed a cross-sectional study of type 2 diabetic patients using structured questionnaires in a Chinese tertiary hospital. A total of 130 patients were enrolled to be interviewed about TPB variables (behavioral, normative, and control beliefs) relevant to medication adherence. Medication adherence was assessed using the eight-item Morisky Medication Adherence Scale (MMAS-8). Spearman's rank correlation was used to assess the association between TPB and MMAS-8. Logistic regression analysis was performed to examine the relationship between different variables and MMAS-8, with statistical significance determined at $P<0.05$.

Results: From 130 eligible Chinese patients with an average age of 60.6 years and a male proportion of $50.8 \%$, a nonsignificant relationship between behavioral, normative, and the most facilitating control beliefs and OAD adherence was found in our study. Having the OADs on hand $(P=0.037)$ was the only facilitating control belief associated with adherence behavior. Being away from home or eating out $(P=0.000)$, not accepting the disease $(P=0.000)$, ignorance of life-long drug adherence ( $P=0.038)$, being busy $(P=0.001)$, or poor memory $(P=0.008)$ were control belief barriers found to be correlated with poor adherence. TPB is the only important determinant influencing OAD adherence among all the factors $(P=0.011)$.

Conclusion: The results indicate that the TPB model could be used to examine adherence to OADs. One facilitating control belief, and most of the barrier control beliefs of TPB were related to medication adherence among Chinese type 2 diabetes inpatients. It will be helpful to understand patients' self-medication and provide methods to develop instruments for identifying factors that influence OAD adherence.

Keywords: type 2 diabetes, medication adherence, theory of planned behavior

\section{Introduction}

Adherence to oral antidiabetic drugs (OADs) is necessary to ensure positive health outcomes, postpone disease progression, and reduce mortality for people living with diabetes. ${ }^{1-3}$ The reality, however, is that poor adherence to drug treatment among patients with diabetes is quite common. A study in Australia showed that $59.6 \%$ of patients omitted their hypoglycemic drugs 3 months before the study interview. ${ }^{4}$ Another study, in the US, found that overall adherence to oral medications for military veterans with diabetes ranged from $42.5 \%$ to $54.1 \% .^{5}$ Since treatment regimens will not work effectively if medications are not taken as prescribed, it is essential to pinpoint the
Correspondence: Naifeng Liu Institute of Cardiovascular Disease, Southeast University Medical School, Nanjing 210000, People's Republic of China

Tel +862583272002

Email liunf@seu.edu.cn 
causes for poor medication adherence, as well as intervention approaches to ensure optimal adherence..$^{6,7}$

The theory of planned behavior (TPB), one of the models used to predict adherence behaviors in patients with chronic diseases, ${ }^{8}$ has been validated as a useful predictor of health behavior. ${ }^{9}$ It is used to understand a range of different adherence behaviors, including adherence to diet, exercise, and drug use. ${ }^{10-12}$ Apart from having been validated repeatedly in a large number of different behavioral domains and subject populations, TPB possesses the advantage of flexibility, as variables can be added to it. ${ }^{9}$

Kagee and van der Merwe ${ }^{13}$ concluded that TPB can explain $23 \%$ of differences in medication adherence among patients with diabetes and hypertension in South Africa. Saal and Kagee ${ }^{14}$ found that TPB was helpful in evaluating medication adherence in patients receiving antiretroviral therapy in South Africa. Nonetheless, studies about TPB in relation to $\mathrm{OAD}$ adherence are rare; a paper has been published reporting that only three previous studies applied the TPB model to patients with diabetes specifically. ${ }^{15}$ Jannuzzi et $\mathrm{al}^{16}$ and Guenette et $\mathrm{al}^{17}$ applied TPB to identify beliefs related to OAD-taking behavior among patients with type 2 diabetes in Brazil and Canada, respectively. Farmer et al ${ }^{18}$ measured the association between TPB and hypoglycemic medication adherence in UK patients with type 2 diabetes and demonstrated that beliefs were important for predicting medication-taking behavior.

The prevalence of adult diabetes is estimated to be $11.6 \%$ (113.9 million) of the Chinese population, ${ }^{19}$ and with changing lifestyles and an aging population, the incidence rates are expected to soar in the next 10 years. Poor blood glucose control could result in an increase in chronic complications and a high cost burden on health care resources. ${ }^{20}$ It is known that only with optimal adherence to medication, full therapeutic benefits of OADs could be achieved. However, the reality is that medication adherence among type 2 diabetic patients is not optimistic, based on a previous study in which Zhou et $\mathrm{al}^{21}$ found that only $47 \%$ of patients in the People's Republic of China had taken $\geq 90 \%$ of their daily OADs as prescribed. Therefore, developing instruments to identify determinants of medication adherence is urgent and essential. While studies on whether TPB can be used to examine medication adherence among patients with Chinese type 2 diabetes are scarce, this study aims to identify influential beliefs associated with OAD adherence through the application of TPB to a Chinese population. We used a cross-sectional survey to, 1) identify beliefs held by Chinese patients with type 2 diabetes and, 2) measure the associations between these beliefs and OAD adherence behavior. We expect that this study will provide more powerful evidence to understand the association between TPB and OAD adherence among Chinese patients with type 2 diabetes.

\section{Patients and methods}

\section{Patient selection}

This was a cross-sectional study conducted among a convenience sample of 130 adults with type 2 diabetes, who were recruited from a tertiary hospital in Changzhou, People's Republic of China. A pharmacist administered all questionnaires and scales to participants via a face-to-face interview at the hospital inpatient department. Patients were included based on the following criteria: 1 ) receiving OAD treatment for at least 3 months, 2) no severe acute complications, 3 ) physically and psychologically capable of engaging in an interview, and 4) agreeing to sign a consent form. The study was carried out in accordance with the First People's Hospital of Changzhou requirements for human subject research.

\section{Medication adherence assessment}

Medication adherence was measured by the eight-item Morisky Medication Adherence Scale (MMAS-8). ${ }^{22}$ The validity and reliability of the Chinese version of the MMAS- 8 have been verified in a Chinese population. ${ }^{23}$ The total score ranges from 0 to 8 , and two levels of adherence were considered based on the following scores: 0 to $\leq 6$ (poor) and 6 to 8 (optimal). ${ }^{24}$

\section{TPB questionnaire}

All salient beliefs were elicited from interviews. Assessments of patients' planned behavior questionnaire were derived from previous TPB research and closely followed previous recommendations. ${ }^{17,18}$ The TPB model assumes that beliefs influence intention and impact behavior. It has been used in the population of type 2 diabetes, who were taking medications in the previous study. ${ }^{18}$ Here, we assessed three types of beliefs: 1) behavioral beliefs (attitudes), assessing the advantages and disadvantages of taking prescribed OADs, 2) normative beliefs, assessing the expectations of others regarding taking prescribed OADs, and 3) control beliefs, assessing factors that can be a barrier or facilitate taking prescribed OADs. All items were scored on a five-point scale from strongly disagree (1) to strongly agree (5).

\section{Sociodemographic and clinical information}

Basic sociodemographic data included sex, age, marital status, education, health insurance status, and monthly income. 
Clinical data included duration of diabetes, number of OADs, and frequency of OAD administration. Basic sociodemographic data and clinical data were collected from interviews.

\section{Statistical analysis}

Data were collected into spreadsheets (Microsoft Excel 2007; Microsoft Corporation, Redmond, WA, USA) and analyzed by SPSS Version 20. Frequencies' statistics were used to evaluate patients' demographic characteristics and adherence scores. Spearman's rank correlation coefficient was employed to measure associations between categorical TPB variables and medication adherence. Binary logistic regression analysis was used to examine association between different variables and medication adherence. The significance level was set at $P<0.05$.

\section{Ethical considerations}

The study was carried out in accordance with the First People's Hospital of Changzhou requirements for human subject research and the Ethics in Research Committee of the First People's Hospital of Changzhou approved the study.

\section{Results}

\section{Sample characteristics}

A total of 130 patients with diabetes were interviewed, of whom $66(50.8 \%)$ were female. The mean age was 60.6 years (range: $34-83$ years). Twenty-two of the participants (16.9\%) had no formal education, and 116 (89.2\%) were married. Approximately half (55 or $42.3 \%$ ) used two types of OADs, and $68(52.3 \%)$ participants took OADs three times or more a day. Based on the MMAS-8, 59 (45.4\%) patients had optimal adherence and 71 (54.6\%) had poor adherence. Table 1 summarizes details of the respondents' background characteristics and percentages of different levels of medication adherence.

\section{Patients' beliefs about taking medication}

Numbers of the patients who reported each of the beliefs are listed in Table 2. Six factors were identified as behavioral beliefs, constituting five advantages and one disadvantage. Advantages included the following beliefs about adhering to the prescribed medication regimen: 1) help to stay well, 2) reduce chances of developing complications from diabetes, 3) control blood glucose, 4) control diabetes, and 5) avoid having to inject insulin. Causing unpleasant side effects, such as hepatic and renal changes, was the only disadvantage belief reported in connection with adhering to the prescribed OAD regimen.
Table I Sociodemographic characteristics of respondents

\begin{tabular}{|c|c|c|c|}
\hline Characteristics & Categories & $\mathbf{n}$ & Frequency (\%) \\
\hline \multirow[t]{2}{*}{ Sex } & Female & 66 & 50.8 \\
\hline & Male & 64 & 49.2 \\
\hline \multirow[t]{5}{*}{ Age, years } & Mean & 60.6 & \\
\hline & $<50$ & 25 & 19.2 \\
\hline & $50-59$ & 27 & 20.8 \\
\hline & $60-69$ & 48 & 36.9 \\
\hline & $\geq 70$ & 30 & 23.1 \\
\hline \multirow[t]{4}{*}{ Educational level } & No formal education & 22 & 16.9 \\
\hline & Primary school & 17 & 13.1 \\
\hline & Senior secondary & 70 & 53.8 \\
\hline & College and above & 21 & 16.2 \\
\hline \multirow[t]{2}{*}{ Marital status } & Married & 116 & 89.2 \\
\hline & Widowed & 14 & 10.8 \\
\hline \multirow[t]{4}{*}{ Monthly income (¥) } & $>2,000$ & 109 & 83.8 \\
\hline & $1,000-2,000$ & 8 & 6.2 \\
\hline & $500-1,000$ & 6 & 4.6 \\
\hline & $<500$ & 7 & 5.4 \\
\hline \multirow[t]{2}{*}{ Health insurance } & Yes & $|2|$ & 93.1 \\
\hline & No & 9 & 6.9 \\
\hline \multirow[t]{3}{*}{ Number of medications } & 1 & 51 & 39.2 \\
\hline & 2 & 55 & 42.3 \\
\hline & $\geq 3$ & 24 & 18.5 \\
\hline \multirow[t]{4}{*}{ Frequency of medication } & Once a day & 23 & 17.7 \\
\hline & Twice a day & 39 & 30.0 \\
\hline & Three times a day & 67 & 51.5 \\
\hline & Four times a day & 1 & 0.8 \\
\hline \multirow[t]{3}{*}{ Duration of diabetes } & $<5$ years & 23 & 17.7 \\
\hline & $5-10$ years & 52 & 40.0 \\
\hline & $\geq 10$ years & 55 & 42.3 \\
\hline \multirow[t]{2}{*}{ Medication adherence } & Poor & 71 & 54.6 \\
\hline & Optimal & 59 & 45.4 \\
\hline
\end{tabular}

Note: Medication adherence was measured by MMAS-8.

Regarding normative beliefs, participants identified three groups as important for their OAD adherence, including medical staff (their doctors and nurses), their spouses, and other family members. Among the three groups, spouse was the most common support group identified in our study.

Eleven factors were identified as control beliefs, constituting five facilitators and six barriers. The five facilitating control beliefs were: 1) having the OADs on hand (eg, in a purse, a pocket, or the car), 2) keeping OADs in one set place at home, 3) having a routine, 4) receiving a periodic reminder from another person, and 5) using a pill dispenser. The six reported answers for not adhering to the medication schedule reveal beliefs that are perceived as barriers to control: 1) Being away from home or eating out, 2) not accepting the disease, 3 ) ignorance of life-long drug adherence, 4) when friends or relatives visit, 5) being busy, and 6) poor memory (Table 2 ). 
Table 2 Correlations between each of the items with elicited beliefs to take medication and medication adherence $(n=130)$

\begin{tabular}{|c|c|c|c|c|}
\hline \multirow[t]{2}{*}{ Variable } & \multirow[t]{2}{*}{$\mathbf{n}$} & \multicolumn{3}{|c|}{ Medication adherence $P(r)^{\#}$} \\
\hline & & Poor & Optimal & Total \\
\hline \multicolumn{5}{|l|}{ Behavioral beliefs (advantages) } \\
\hline It would help me to stay well & 39 & $0.137(-0.185)$ & $0.419(0.103)$ & $0.554(-0.052)$ \\
\hline It would reduce my chances of developing complications from diabetes & 34 & $0.459(-0.093)$ & $0.760(-0.039)$ & $0.446(-0.067)$ \\
\hline It would keep my blood sugar under control & 98 & $0.766(0.037)$ & $0.739(0.042)$ & $0.547(-0.053)$ \\
\hline It would keep my diabetes under control & 61 & $0.872(0.020)$ & $0.570(0.072)$ & $0.626(0.043)$ \\
\hline It would help me avoid injecting insulin & 17 & $0.417(0.102)$ & $0.672(-0.054)$ & $0.782(0.024)$ \\
\hline It would cause me unpleasant side effects (eg, hepatic or renal injury and weight gain) & 72 & $0.456(-0.093)$ & $0.335(-0.123)$ & $0.227(-0.107)$ \\
\hline \multicolumn{5}{|l|}{ Normative beliefs (expectations of others) } \\
\hline My doctor or nurse would approve that I am taking my diabetes medicines regularly & 6 & $0.893(-0.017)$ & $0.5 I I(-0.084)$ & $0.590(-0.048)$ \\
\hline $\begin{array}{l}\text { Members of my family or close relatives would approve that I am taking my diabetes } \\
\text { medicines regularly }\end{array}$ & 42 & $0.564(0.072)$ & $0.934(-0.011)$ & $0.657(-0.039)$ \\
\hline $\begin{array}{l}\text { My wife/husband/partner would approve that I am taking my diabetes medicines } \\
\text { regularly }\end{array}$ & 95 & $0.039(0.255)$ & $0.774(0.037)$ & $0.115(0.139)$ \\
\hline \multicolumn{5}{|l|}{ Control beliefs } \\
\hline \multicolumn{5}{|l|}{ Facilitating factors } \\
\hline Having the OADs on hand & 21 & $0.433(-0.098)$ & $0.020(-0.289)$ & $0.037(-0.183)$ \\
\hline Keep OADs in a fixed position at home & 111 & $0.672(-0.053)$ & $0.395(0.108)$ & $0.821(0.020)$ \\
\hline Have a routine & 4 & $0.202(0.159)$ & $0.761(0.039)$ & $0.274(0.097)$ \\
\hline Have somebody to remind me & 4 & $0.508(0.083)$ & $0.773(0.037)$ & $0.46 I(0.065)$ \\
\hline Use a pill dispenser & 16 & $0.557(-0.074)$ & $0.558(0.075)$ & $0.974(-0.003)$ \\
\hline \multicolumn{5}{|l|}{ Barriers } \\
\hline Being away from home or eating out & 39 & $0.006(-0.332)$ & $0.045(-0.25 \mathrm{I})$ & $0.000(-0.321)$ \\
\hline Not accepting the disease & 9 & $0.017(-0.294)$ & $0.000(-0.503)$ & $0.000(-0.405)$ \\
\hline Ignorance of life-long drug adherence & 6 & $0.004(-0.350)$ & $0.711(-0.047)$ & $0.038(-0.183)$ \\
\hline When friends or relatives visit & 5 & $0.048(-0.244)$ & $0.764(-0.038)$ & $0.583(-0.170)$ \\
\hline When busy & 30 & $0.180(-0.167)$ & $0.000(-0.444)$ & $0.001(-0.300)$ \\
\hline Poor memory & 24 & $0.007(-0.330)$ & $0.133(-0.190)$ & $0.008(-0.230)$ \\
\hline
\end{tabular}

Notes: Medication adherence was measured by MMAS-8. "Spearman's rank correlation analysis.

Abbreviation: OADs, oral antidiabetic drugs.

\section{Correlations between beliefs and}

\section{adherence}

One facilitating, and most of the barrier control beliefs were associated with a reduction in medication adherence (Table 2). There were significant negative associations between OAD adherence with the beliefs "being away from home or eating out $(P=0.000, r=-0.0321)$ ", "not accepting the disease $(P=0.000, r=-0.405)$ ", "when busy $(P=0.001, r=-0.300)$ ", or "poor memory $(P=0.008$, $r=-0.230)$ ". The beliefs "having the OADs on hand ( $P=0.037, r=-0.183$ )", "ignorance of life-long drug adherence $(P=0.038, r=-0.183)$ " were also associated with a lower MMAS-8 score $(P<0.05)$. Relationship between different belief items and different levels of adherence is listed in Table 2.

\section{Correlations between variables and adherence}

There was a significant correlation between TPB model and level of adherence (odds ratio $=0.935$, [95\% CI: $0.888-0.985$ ], $P=0.011$ ). No other variables were found to be related to adherence. Details of results of binary logistic regression analysis are provided in Table 3.

\section{Discussion}

The present study shows that $45.4 \%$ of patients with type 2 diabetes reported adherence to OADs, which is similar to the numbers reported in studies conducted in Mexico $(41 \%)^{25}$

Table 3 Logistic regression analysis between different variables and medication adherence

\begin{tabular}{lllll}
\hline Variable & P-value & $\begin{array}{l}\text { Odds } \\
\text { ratio }\end{array}$ & \multicolumn{2}{c}{$\mathbf{9 5 \%} \mathbf{~ C l}$} \\
\cline { 4 - 5 } & & Lower & Upper \\
\hline TPB & $0.01 \mathrm{I}$ & 0.935 & 0.888 & 0.985 \\
Sex & $0.71 \mathrm{I}$ & 1.173 & 0.504 & 2.732 \\
Age & 0.072 & 1.037 & 0.997 & 1.079 \\
Marital status & 0.389 & 1.368 & 0.671 & 2.791 \\
Duration & 0.704 & 0.986 & 0.918 & 1.059 \\
Education & 0.842 & 0.952 & 0.584 & 1.550 \\
Monthly income & 0.341 & 1.360 & 0.722 & 2.564 \\
Insurance & 0.263 & 0.640 & 0.293 & 1.398 \\
Number of medications & 0.784 & 0.927 & 0.541 & 1.589 \\
Frequency of medication & 0.268 & 1.359 & 0.790 & 2.339 \\
\hline
\end{tabular}

Abbreviations: TPB, theory of planned behavior; $\mathrm{Cl}$, confidence interval. 
and in Malaysia (47\%). ${ }^{26}$ The adherence rate among patients with diabetes is inadequate in most of the countries, therefore, it is essential and imperative to identify factors influencing medication adherence, which may help to develop effective interventions and enhance patients' treatment outcomes.

The findings showed that not all TPB factors in this study were significantly related to OAD adherence, which is consistent with others. ${ }^{9}$ The main beliefs associated with adherence to OADs were the barriers to control beliefs; this finding may help in designing interventions to evade these beliefs. Rich et $\mathrm{al}^{8}$ found that stronger support was required for some factors more than others, similar to our findings. For example, more patients believed that medication would keep their blood sugar under control than other behavioral beliefs; this may result in different associations between belief items and OAD adherence.

In regard to behavioral beliefs, none of the advantage beliefs were found to be related to medication adherence. In contrast to our observations, Farmer et $\mathrm{al}^{18}$ confirmed that avoiding long-term complications and controlling glycemia were two favorable behavioral beliefs that could improve OAD adherence in an English population. This difference in findings may stem from a difference in race and diabetes consciousness among participants.

In our study, patients saw side effects of OADs as a disadvantage. Jannuzzi et $\mathrm{al}^{16}$ found that $82.4 \%$ of their study participants believed that taking their diabetes medications regularly would cause unpleasant side effects; Farmer et al ${ }^{13}$ found a much lower percentage $-32.8 \%$ - while we found $57.7 \%(75 / 130)$ in our study, which was approximately midway between them. Beliefs about hepatic and renal changes after taking OADs contributed to a common worry among patients in our study, but this belief bore no relationship with reported medication adherence, since people usually choose to continue taking OADs to control their diabetes, rather than worrying excessively about side effects.

With regard to normative beliefs, although social and peer support has been shown to have positive associations with medical adherence ${ }^{27,28}$ and glycemic control among type 2 diabetics, ${ }^{29,30}$ this study found otherwise. First, physicians and nursing staff were not identified as influential for medication adherence, which may be related to the low rates of support from health professionals (6/130) or family members (42/130). Second, although support from one's spouse was estimated to be $73.1 \%(95 / 130)$, it was found to have no direct relation to medication adherence, in contrast with previous studies. A survey in Korea has concluded that social support-enhancing interventions can promote medication adherence effectively. ${ }^{31}$ Further study is required to resolve the discrepancy.

With regard to control beliefs, "carrying the OADs whenever leaving home" and "keeping OADs in one set place at home" were two frequently favored control beliefs, which is consistent with previous work. ${ }^{18}$ The former was shown to be the only positive belief related to medication adherence among all facilitating control beliefs, although it was deemed important only by patients reporting optimal adherence. Five barrier beliefs were significant related barriers to medication adherence; "ignorance of life-long drug adherence" and "poor memory" were two related beliefs among patients with poor adherence. These results suggest that actions involving self-discipline may be more beneficial to understanding adherence-related behavior, and that different levels of adherence must be taken into account when considering this. Facilitating factors may help in designing interventions to enhance adherence, while barriers to control beliefs may help to identify people with poor adherence level and provide directions to enhance it.

The logistic analysis findings showed that TPB was the only one positive significant determinant related to adherence, which suggests that TPB could be a useful model for adjusting clinicians' interventions in view of their patients' beliefs. Although occupation, income, and number of OADs taken per day have been found to be factors affecting level of adherence, ${ }^{32}$ our study found otherwise. Although Wong et $\mathrm{al}^{24}$ found that age is the only factor that correlated with medication adherence among the characteristics of Chinese patients, our study found no correlation between age and medication adherence $(P=0.072)$. A larger sample may be necessary to detect an association between age and adherence.

We elicited patients' beliefs regarding their OAD adherence based on the TPB conceptual model. One of the strengths of our study is the use of TPB to analyze its associations with OAD adherence in a Chinese diabetic population, for the first time. In addition, our study questionnaire was conducted in the inpatient department, allowing us enough time to interview participants, who may have focused well on the questions. As a result, the information we elicited about commonly held beliefs may have been relatively complete.

\section{Limitations}

However, there are also several limitations that warrant consideration. Our participants were recruited from a region within a tertiary city in the People's Republic of China; therefore, people in other large cities or in rural regions were not represented in our study sample, precluding the discovery of 
possible other new beliefs affecting medication adherence. In addition, only hospitalized patients were included in our study; outpatients medication adherence is unknown. Further studies will be needed to assess beliefs and OAD adherence in these areas.

\section{Conclusion}

In this cross-sectional study, we used a predictive theoretical model to elicit and identify beliefs about taking OADs regularly, and thereby assess the correlations between TPB and OAD adherence. Our results showed that TPB model could be used to examine adherence to OADs. Positive control beliefs related to adherence provide ideas for developing intervention approaches to support adherence. It will be helpful to understand whether patients' self-medication actions, including acceptance or rejection of drug therapy, contribute to finding instruments for identifying factors that influence OAD adherence, and explore whether these determinants may aid the development of OAD adherence-enhancing interventions further. Future work should apply TPB to patients in other geographical regions to predict OADs-adherence behavior in the People's Republic of China.

\section{Acknowledgments}

The authors thank the staff at the Department of Endocrinology, the First People's Hospital of Changzhou, for their assistance and cooperation with the studies. We thank Doctor Honghong Yao, Department of Pharmacology, Medical School of Southeast University, Nanjing, Jiangsu, People's Republic of China, for her assistance.

\section{Disclosure}

The authors report no conflicts of interest in this work.

\section{References}

1. Doggrell SA, Warot S. The association between the measurement of adherence to anti-diabetes medicine and the HbA1c. Int J Clin Pharm. 2014;36(3):488-497.

2. Mendys P, Zullig LL, Burkholder R, Granger BB, Bosworth HB. Medication adherence: process for implementation. Patient Prefer Adherence. 2014;8(28):1025-1034.

3. Manan MM, Husin AR, Alkhoshaiban AS, Al-Worafi YM, Ming LC. Interplay between oral hypoglycemic medication adherence and quality of life among elderly Type 2 diabetes mellitus patients. J Clin Diagn Res. 2014;8(12):JC05-JC09.

4. Pihau-Tulo ST, Parsons RW, Hughes JD. An evaluation of patients' adherence with hypoglycemic medications among Papua New Guineans with Type 2 diabetes: influencing factors. Patient Prefer Adherence. 2014; 8(16):1229-1237.

5. Melzer AC, Uman J, Au DH. Adherence to oral medications for hypertension and diabetes in veterans with comorbid airflow limitation. Ann Am Thorac Soc. 2015;6(12):831-837.
6. Zullig LL, Gellad WF, Moaddeb J, et al. Improving diabetes medication adherence: successful, scalable interventions. Patient Prefer Adherence. 2015;9(23):139-149.

7. Polonsky WH. Poor medication adherence in diabetes: what's the problem? J Diabetes. 2015;6(7):777-778.

8. Rich A, Brandes K, Mullan B, Hagger MS. Theory of planned behavior and adherence in chronic illness: a meta-analysis. J Behav Med. 2015;38(4):673-688.

9. Ajzen I, Fishbein M. Questions raised by a reasoned action approach: comment on Ogden (2003). Health Psychol. 2004;23(4):431-434.

10. Chevance G, Caudroit J, Romain AJ, Boiche J. The adoption of physical activity and eating behaviors among persons with obesity and in the general population: the role of implicit attitudes within the Theory of Planned Behavior. Psychol Health Med. Epub 2016 Mar 7:1-6.

11. Kopelowicz A, Zarate R, Wallace CJ, Liberman RP, Lopez SR, Mintz J. Using the theory of planned behavior to improve treatment adherence in Mexican Americans with schizophrenia. J Consult Clin Psychol. 2015; 83(5):985-993.

12. Ahmad MH, Shahar S, Teng NI, Manaf ZA, Sakian NI, Omar B. Applying theory of planned behavior to predict exercise maintenance in sarcopenic elderly. Clin Interv Aging. 2014;9:1551-1561.

13. Kagee A, van der Merwe M. Predicting treatment adherence among patients attending primary health care clinics: the utility of the Theory of Planned Behavior. S Afr J Psychol. 2006;36(4):699-714.

14. Saal W, Kagee A. The applicability of the Theory of Planned Behaviour in predicting adherence to ART among a South African sample. J Health Psychol. 2012;17(3):362-370.

15. Guenette L, Breton MC, Guillaumie L, Lauzier S, Gregoire JP, Moisan J. Psychosocial factors associated with adherence to non-insulin antidiabetes treatments. J Diabetes Complications. 2016;30(2):335-342.

16. Jannuzzi FF, Rodrigues RC, Cornelio ME, Sao-Joao TM, Gallani MC. Beliefs related to adherence to oral antidiabetic treatment according to the Theory of Planned Behavior. Rev Lat Am Enfermagem. 2014;22(4): 529-537.

17. Guenette L, Lauzier S, Guillaumie L, Giguere G, Gregoire JP, Moisan J. Patients' beliefs about adherence to oral antidiabetic treatment: a qualitative study. Patient Prefer Adherence. 2015;9(10):413-420.

18. Farmer A, Kinmonth AL, Sutton S. Measuring beliefs about taking hypoglycaemic medication among people with Type 2 diabetes. Diabet Med. 2006;23(3):265-270.

19. Xu Y, Wang L, He J, et al. Prevalence and control of diabetes in Chinese adults. JAMA. 2013;310(9):948-959.

20. Rhee MK, Slocum W, Ziemer DC, et al. Patient adherence improves glycemic control. Diabetes Educ. 2005;31(2):240-250.

21. Zhou Y, Liao L, Sun M, He G. Self-care practices of Chinese individuals with diabetes. Exp Ther Med. 2013;5(4):1137-1142.

22. Sakthong P, Chabunthom R, Charoenvisuthiwongs R. Psychometric properties of the Thai version of the 8-item Morisky Medication Adherence Scale in patients with Type 2 diabetes. Ann Pharmacother. 2009;43(5):950-957.

23. Wang J, Bian RW, Mo Y. Validation of the Chinese version of the eight-item Morisky medication adherence scale in patients with type 2 diabetes mellitus. J Clin Gerontol Geriatr. 2013;4(4):119-122.

24. Wong $\mathrm{MC}, \mathrm{Wu} \mathrm{CH}$, Wang $\mathrm{HH}$, et al. Association between the 8-item Morisky medication adherence scale (MMAS-8) score and glycaemic control among Chinese diabetes patients. J Clin Pharmacol. 2015;55(3): 279-287.

25. Hernandez-Ronquillo L, Tellez-Zenteno JF, Garduno-Espinosa J, Gonzalez-Acevez E. Factors associated with therapy noncompliance in Type-2 diabetes patients. Salud Publica Mex. 2003;45(3):191-197.

26. Ahmad NS, Ramli A, Islahudin F, Paraidathathu T. Medication adherence in patients with type 2 diabetes mellitus treated at primary health clinics in Malaysia. Patient Prefer Adherence. 2013;7:525-530.

27. Osamor PE. Social support and management of hypertension in South-west Nigeria. Cardiovasc J Afr. 2015;26(1):29-33. 
28. Chisholm MA, Williamson GM, Lance CE, Mulloy LL. Predicting adherence to immunosuppressant therapy: a prospective analysis of the theory of planned behaviour. Nephrol Dial Transplant. 2007;22(8): 2339-2348.

29. Qi L, Liu Q, Qi X, Wu N, Tang W, Xiong H. Effectiveness of peer support for improving glycaemic control in patients with type 2 diabetes: a meta-analysis of randomized controlled trials. BMC Public Health. 2015;15(6):471.

30. Yin J, Wong R, Au S, et al. Effects of providing peer support on diabetes management in people with type 2 diabetes. Ann Fam Med. 2015; 13(suppl 1):S42-S49.
31. Kim CJ, Schlenk EA, Kim DJ, Kim M, Erlen JA, Kim SE. The role of social support on the relationship of depressive symptoms to medication adherence and self-care activities in adults with Type 2 diabetes. $J A d v$ Nurs. 2015;71(9):2164-2175.

32. Bruce SP, Acheampong F, Kretchy I. Adherence to oral anti-diabetic drugs among patients attending a Ghanaian teaching hospital. Pharm Pract (Granada). 2015;13(1):533.

\section{Publish your work in this journal}

Patient Preference and Adherence is an international, peer-reviewed, open access journal that focuses on the growing importance of patient preference and adherence throughout the therapeutic continuum. Patient satisfaction, acceptability, quality of life, compliance, persistence and their role in developing new therapeutic modalities and compounds to optimize clinical outcomes for existing disease states are major areas of interest for the journal. This journal has been accepted for indexing on PubMed Central. The manuscript management system is completely online and includes a very quick and fair peer-review system, which is all easy to use. Visit http://www. dovepress.com/testimonials.php to read real quotes from published authors.

\footnotetext{
Submit your manuscript here: http://www.dovepress.com/patient-preference-and-adherence-journal
} 